\title{
Investigar la traducción de productos culturales chinos: retos y dificultades metodológicas en la creación de bases de datos sobre cine y literatura
}

\section{Researching the Translation of Chinese Cultural Products: Methodological Challenges and Difficulties in the Creation of Cinema and Literature Database}

\author{
Helena Casas-Tost, Sara Rovira-Esteva, Mireia Vargas-Urí \\ Universitat Autònoma de Barcelona \\ Helena.Casas@uab.cat / Sara.Rovira@uab.cat / Mireia.Vargas@uab.cat
}

Recibido: marzo-2020. Revisado: abril-2020. Aceptado: mayo-2020.

Resumen: En un contexto en el que las Humanidades Digitales están cambiando las metodologías tradicionales de investigación, en este artículo describimos dos bases de datos de literatura y cine de acceso abierto que ponen al alcance de toda la comunidad científica dos recursos de gran valor traductológico, bibliográfico y documental para estudiar dos ámbitos clave de la producción cultural china, así como su introducción en el contexto sociocultural español. Este trabajo tiene por objetivo explicar las razones que motivaron este proyecto, los criterios seguidos en su diseño y los diferentes niveles de análisis que ofrece para la investigación. Para ello, se hace un repaso de los antecedentes y de los diferentes recursos parecidos existentes, también se detalla y justifica la metodología seguida en cada una de las bases de datos y, finalmente, se resume la aportación y potencial investigador que representan tanto para la traductología como para otras disciplinas afines.

Palabras clave: literatura china; cine chino; bases de datos de traducción; paratextos.

Helena CASAs-Tost, Sara Rovira-Esteva y Mireia VARGAS-URPI

Investigar la traducción de productos culturales chinos: retos y dificultades metodológicas... 


\begin{abstract}
In a context in which Digital Humanities are changing traditional research methodologies, this article presents two open access databases on Chinese literature and cinema, two key areas of Chinese cultural production. The information contained in these two resources, available to the entire scientific community, is not only valuable for Translation Studies scholars (because they include data on their introduction in the Spanish sociocultural context), but also from a bibliographic and documentary perspective. This paper aims to explain the reasons that motivated this project, the criteria followed in the design of the databases and the different levels of analysis they offer for researchers. A review of the state of the art and of different similar existing resources is carried out; the methodology followed in each of the databases is detailed and justified, and, finally, their overall contribution and research potential are summarized.
\end{abstract}

Keywords: Chinese literature; Chinese cinema; translation databases; paratexts.

\title{
1. INTRODUCCIÓN
}

En la comunicación entre culturas, la literatura y el cine se han convertido en las dos manifestaciones culturales por excelencia: nos permiten forjar una imagen del Otro a partir de su propio punto de vista, ya sea mediante una obra escrita o filmada. Cuando las culturas no comparten una lengua en común, la contribución del traductor es indispensable. En este sentido, estudiar la traducción nos permite entender cómo se establece esta comunicación entre culturas.

En el caso de la traducción literaria y audiovisual entre el chino y el español, la inexistencia de una base de datos exhaustiva de todas las traducciones realizadas en cada uno de estos dos ámbitos dificultaba llegar a conclusiones generalizables que dieran cuenta, por ejemplo, de los géneros más traducidos o de los autores o directores con mayor proyección en España. La información detallada sobre qué obras, cómo y cuándo se han traducido, quién ha realizado la traducción, qué editoriales o distribuidoras las promueven o cómo se han presentado dichas obras en nuestro contexto, entre otros aspectos, ha permanecido dispersa y, en muchos casos, oculta al investigador. Por consiguiente, resultaba muy complicado formarse una idea global de la traducción literaria y audiovisual del chino en nuestro país, pero también acceder a determinados detalles relacionados con las traducciones, en especial, las más antiguas. Por todo ello, hace algunos años el grupo de investigación en Traducción del chino al catalán/castellano (TXICC) ${ }^{1}$ de la UAB se propuso crear dos bases de datos donde recopilar de modo sistemático información sobre la literatura y el cine traducidos en España.

Helena CAsas-Tost, Sara Rovira-Esteva y Mireia VARGAS-URPI Investigar la traducción de productos culturales chinos: retos y dificultades metodológicas...
CLINA

vol. 6-1, June 2020, 17-36

elSSN: 2444-1961

Ediciones Universidad de Salamanca - CC BY-NC-ND 
Así pues, el objetivo principal de estas bases de datos es proporcionar información lo más exhaustiva y precisa posible sobre la traducción de obras literarias y fílmicas, con el propósito último y ético como investigadoras en el campo de la Traducción e Interpretación de dar relevancia y visibilidad a la labor del traductor, a menudo invisibilizada en los canales de distribución, pero realmente esencial para que estos productos culturales puedan cruzar fronteras y ser consumidos en nuestro país.

En este trabajo se presentan ambas bases de datos: su estructura, características y funcionalidades principales, los aspectos comunes y sus rasgos distintivos, las dificultades y retos metodológicos que hemos tenido que resolver en su creación, así como la aportación que suponen respecto a otras bases de datos o trabajos previos y su potencial futuro en tanto que productos y herramientas de investigación.

\section{ESTUDIOS PREVIOS SOBRE RECEPCIÓN DE LITERATURA Y CINE CHINO TRADUCIDOS}

En cuanto a los estudios sobre traducciones de literatura china, cabe señalar que la gran mayoría de trabajos previos se han centrado en obras $u$ autores concretos. Es el caso, por ejemplo, de tesis como las de Chang Yun-chi (2012), sobre la traducción del lenguaje no verbal de la novela Xi You Ji (西游记, Viaje al Oeste) y Ku Meng-hsuan (2006), sobre la traducción de los elementos culturales de Hong Lou Meng (红楼梦, Sueño en el pabellón rojo) o los trabajos de Mi Tian (2017; 2018), sobre las traducciones del chino al español de Marcela de Juan, entre otros. Gabriel García-Noblejas también ha dedicado varios artículos de la revista El Trujamán a figuras históricas de la traducción del chino en España, como han sido la ya mencionada Marcela de Juan (García-Noblejas 2010), Carmelo Elorduy (García-Noblejas 2011), Fray Juan Cobo (García-Noblejas 2012a) o Fray Domingo Fernández de Navarrete (García-Noblejas 2012b).

En cambio, es más difícil encontrar estudios que presenten una panorámica de las traducciones de la literatura china al español. En este sentido, destacan los trabajos de Marin-Lacarta (2012; 2014; 2018) y Wang Chenying (2013; 2016), así como las recopilaciones de Arbillaga (2003) y Orlando (2013). Marin-Lacarta $(2012,114)$ parte de un corpus de 84 obras escritas en chino después de 1917, fecha de inicio de la revolución literaria, traducidas al español o al catalán hasta 2009. Este corpus le permite fijarse en aspectos clave como la recurrencia de las traducciones mediadas, con un incremento entre 2001 y 2009, contrario a lo que sería la evolución esperada (Marin-Lacarta 2012, 284), pero también le permite profundizar en la recepción de la literatura china en España mediante el análisis de algunos paratextos como pueden ser los prólogos. Wang Chenying (2013; 2016) se basa en un corpus de 69 obras de 41 autores, extraídas de las bases de datos del ISBN del Ministerio de Cultura de España y del Index Translationum de la Unesco. La conclusión principal a la que llega esta autora es que la traducción del chino es muy minoritaria en comparación con otras

Helena CASAS-Tost, Sara Rovira-EsteVA y Mireia VARGAS-URPI Investigar la traducción de productos culturales chinos: retos y dificultades metodológicas...
CLINA

vol. 6-1, June 2020, 17-36

elSSN: 2444-1961

Ediciones Universidad de Salamanca - CC BY-NC-ND 
lenguas, como pueden ser el inglés o el francés. Por su parte, Arbillaga (2003) realiza el estudio más amplio hasta la fecha sobre la traducción de obras chinas en nuestro país, no solo por la variedad tipológica de géneros incluidos, sino también por el lapso temporal que abarca (desde la primera traducción de la que se tiene constancia hasta finales del siglo XX). Finalmente, Orlando (2013) actualiza una lista realizada por la biblioteca Luis Ángel Arango en 2005 con ocasión de la feria del libro de Bogotá que tuvo a China como país invitado, pero se trata de un mero inventario de obras clasificadas por géneros dirigido al gran público.

Los estudios sobre cine que se han realizado en España parten, sobre todo, de una perspectiva descriptiva de la historia, evolución o análisis del cine chino, como pueden ser las monografías centradas en la historia del cine chino de Sazatornil y Alonso (2012), o la más reciente de Planas (2019), sin tener realmente en cuenta qué proporción de las películas analizadas o descritas se han podido ver traducidas en alguna modalidad al español. En este sentido, Planas utiliza prioritariamente el título en inglés de los filmes, seguido del título en caracteres en la ficha de las películas, y solamente incluye el título en español en casos muy conocidos - por ejemplo, la película Sorgo rojo, dirigida por Zhang Yimou (张艺谋) (Planas 2019, 218) - y como alternativa al título en inglés en el cuerpo del texto. En cambio, Sazatornil y Alonso (2012) incluyen, por defecto, una traducción propia al español a partir del título en inglés. Estas traducciones no siempre se corresponden con el título con el que se ha acabado difundiendo el film en español, como es el caso de Beiqing Chengshi (悲情城市, A City of Sadness), traducida como Tierra de desdicha (Sazatornil y Alonso 2012, 124), a pesar de que se comercializó en España tanto con el nombre en inglés como con el título de Ciudad doliente. En otros casos, la inclusión de una traducción al español del título a pesar de ser películas que no se han proyectado en esta lengua o incluso el uso del inglés como lengua de referencia prioritaria a veces dificulta la identificación de los filmes. Es el caso, por ejemplo, de Gei Kafei Jia Dian Tang (给咖啡加点糖), del director Sun Zhou (孙周), una película sin título oficial en otras lenguas, que aparece en el libro con la traducción literal en inglés (Add Sugar to your Coffee) y al español (Pon azúcar al café) (Sazatornil y Alonso 2012, 112). La única aproximación a la cuestión de la recepción del cine chino en estas obras la encontramos en Sazatornil y Alonso (2012), que incluyen cinco entrevistas a directores chinos en las que se aborda la pregunta de « ¿Por qué cree que el cine chino no tiene éxito comercial en Occidente y sin embargo se lleva premios en festivales?».

De entre los pocos estudios académicos que sí ponen el foco en la recepción del cine chino, cabe señalar el trabajo de Codó (2009) sobre cine asiático, en general, y el de Casas-Tost y Rovira-Esteva (2019), basado en una versión previa de la base de datos que presentamos en el tercer apartado y que contaba, aproximadamente, con la mitad de entradas de las que tenía en el momento de redactar este artículo. Del estudio de Codó (2009) cabe destacar la identificación del papel de los festivales en la difusión de cine asiático en general, un aspecto que también abordan Casas-Tost y Rovira-Esteva (2019), así como la importancia del cine de género. En este caso, Codó (2009,

Helena CAsas-Tost, Sara Rovira-EsteVa y Mireia VARGAS-URPI Investigar la traducción de productos culturales chinos: retos y dificultades metodológicas...
CLINA

vol. 6-1, June 2020, 17-36

elSSN: 2444-1961

Ediciones Universidad de Salamanca - CC BY-NC-ND 
6) explica que «[l]as cintas de terror, los thrillers policíacos y las aventuras con artes marciales, empiezan su singladura en el Oeste en festivales especializados y como fenómeno de culto", aunque se acaban popularizando entre públicos más amplios. En el caso del cine chino, ambos artículos coinciden en la popularidad del género de las artes marciales fuera de China, lo que ha facilitado la importación de muchos filmes de este género en el caso concreto de España (Casas-Tost y Rovira-Esteva 2019, 596).

En el ámbito de los estudios de traducción audiovisual, las investigaciones sobre la traducción de cine chino al español son prácticamente inexistentes, sobre todo si las comparamos con los trabajos que se han realizado en otras combinaciones lingüísticas. Una de las pocas aportaciones en este ámbito es la tesis de Wu Sian-Huang (2013) que se centra en el traslado de los elementos culturales en la traducción para subtítulos de seis películas chinas y utiliza cuestionarios para analizar la recepción de los subtítulos al español de Rebeldes del dios Neón de Tsai Ming-Liang (蔡明亮). Así pues, en comparación con el ámbito de la traducción literaria, y siendo conscientes de que existe cierto volumen de literatura gris (tesinas de máster o Tesis Doctorales inéditas o con poca difusión), los estudios sobre traducción audiovisual de cine chino al español son mucho más escasos.

\section{LAS BASES DE DATOS EN LOS ESTUDIOS DE TRADUCCIÓN}

Además de los trabajos académicos, tenemos a nuestra disposición otro tipo de fuentes de información en formato digital, como son las bases de datos, páginas web y blogs. En cuanto a la traducción literaria, actualmente existen dos bases de datos bibliográficas de referencia: Translation Studies Bibliography (TSB) y BITRA (Bibliografía de Traducción e Interpretación), de pago y de acceso abierto, respectivamente. Dentro del ámbito específico de la interpretación y de la accesibilidad a los medios, contamos con la Conference Interpreting Research Information Network (CIRIN) y la Media Accessibility Platform (MAP), respectivamente. Estas iniciativas han marcado un punto de inflexión porque han permitido que en los últimos años investigadores de esta área de conocimiento hayan empezado a realizar estudios bibliométricos y de análisis meta-científico. Sin embargo, tal como apuntan Rovira-Esteva y Franco Aixelà (2018, 117), no es lo mismo la bibliometría de los estudios de traducción que la bibliometría de traducciones. Para poder llevar a cabo el segundo tipo de estudios, hacen falta bases de datos digitales completas y actualizadas de las traducciones existentes. En este sentido, Poupaud, Pym y Torres Simón (2009) ponen de manifiesto cuán diferentes pueden ser los resultados de una investigación en función de la base de datos que se utiliza. En el ámbito de la traducción literaria, disponemos de diferentes fuentes de información, como el Index Translationum de la UNESCO, que es una base de datos de traducciones generalista e internacional. También existen iniciativas centradas en la traducción literaria de territorios concretos, como la Irish Translation Database Trasna o

Helena CASAS-Tost, Sara ROVIRA-EsteVA y Mireia VARGAS-URPI Investigar la traducción de productos culturales chinos: retos y dificultades metodológicas...
CLINA

vol. 6-1, June 2020, 17-36

elSSN: 2444-1961

Ediciones Universidad de Salamanca - CC BY-NC-ND 
la Canadian Bibliography y, sin ir más lejos, la Biblioteca de Traducciones Españolas de la Fundación Biblioteca Virtual Miguel de Cervantes, la Biblioteca de Traductores (fondo histórico digital de traducciones ibéricas y americanas), la Biblioteca de Traducción Galega elaborada por el grupo de investigación BITRAGA, la Literatura universal en català del PEN catalán o el TRAC², del Institut Ramon Llull, con todas las traducciones del catalán a otras lenguas, por poner solo algunos ejemplos. En el ámbito español también se pueden consultar los catálogos del ISBN y de la Biblioteca Nacional de España (BNE), aunque las fichas no siempre ofrecen información sistemática sobre la traducción.

Además de estas bases de datos, cabe mencionar también recursos en línea como China traducida y por traducir ${ }^{3}$, que, aparte de los anuarios donde se compilan todas las traducciones del chino al español que se publican cada año desde 2013, lista obras chinas clásicas y contemporáneas merecedoras de ser traducidas al español, recoge una breve biografía de los autores chinos, publica traducciones de textos chinos cortos y una revista semestral sobre literatura china y su traducción al español, así como muchos otros recursos sobre este ámbito.

Por otra parte, para investigar en el ámbito de la traducción audiovisual, podemos recurrir a plataformas internacionales como Filmaffinity, Internet Movie Database (IMDb) o la china Movie Douban (豆瓣电影, Douban Dianying), que, lamentablemente, no incluyen datos sobre la traducción. Aparte de estas fuentes, se pueden consultar las bases de datos de los distintos festivales de cine o filmotecas, siempre que las tengan en línea. En cuanto a iniciativas promovidas desde España tenemos sobre todo espacios web, entre los que destaca la labor realizada por CineAsia ${ }^{4}$, más bien de carácter divulgativo, cuyo objetivo es difundir el cine asiático en España, con una recopilación anual de las películas más destacadas, incluyendo todas las de origen chino que llegan a nuestras pantallas, además de reseñas, críticas, entrevistas y otros productos, como el anuario que publican desde 2014. Centrado solamente en el cine de origen chino tenemos el blog Madeinchina ${ }^{5}$ realizado entre 2009 y 2012 o el más reciente Chinese film database (Ortells-Nicolau, s.d.) ${ }^{6}$, con recursos cinematográficos para la docencia y la investigación sobre China. El proyecto China Cult.es ${ }^{7}$ es otra base de datos que tiene como objetivo identificar, seleccionar y sistematizar las producciones culturales realizadas en el marco de las sinergias y conexiones entre China y España, desde el siglo XX hasta la actualidad, aunque no incluye películas traducidas como tales. Pese a constituir interesantes iniciativas para recabar información sobre el cine chino, no pueden considerarse recursos sobre la traducción de cine chino propiamente dichos.

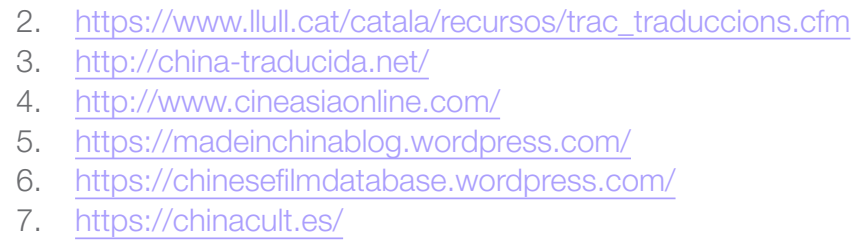

Helena CASAs-Tost, Sara Rovira-EsteVA y Mireia VARGAS-URPI Investigar la traducción de productos culturales chinos: retos y dificultades metodológicas...
CLINA

vol. 6-1, June 2020, 17-36

elSSN: 2444-1961

Ediciones Universidad de Salamanca - CC BY-NC-ND 
Hasta la fecha no nos consta, pues, la existencia de ninguna base de datos ni recurso específico, exhaustivo y en constante actualización de la traducción literaria o audiovisual entre el chino y las lenguas oficiales del Estado español.

\section{DESCRIPCIÓN DE LAS BASES DE DATOS}

\subsection{Aspectos metodológicos generales}

Desde el punto de vista metodológico, las bases de datos son fruto de un proceso de investigación bibliográfica y documental que se ha prolongado durante varios años. Su origen se remonta a una lista de libros y cintas de vídeo en VHS que las investigadoras del grupo compartían para su uso personal. Cuando el volumen de obras fue aumentando y se constató el potencial para la investigación de inventarios más completos y actualizados, se crearon sendas hojas de cálculo en Excel, una para la literatura y otra para el cine, en la que cada fila correspondía a una obra (iteraria o cinematográfica) y en las distintas columnas se anotaban los datos que se pretendían recopilar de cada obra, de acuerdo con las posibilidades que pudiesen ofrecer para la investigación. Las hojas de cálculo han sido dinámicas y han ido dando cabida a nuevas obras; también se han ido añadiendo columnas con nuevos campos de información que podían ser útiles para su análisis. Paralelamente, se crearon carpetas para recopilar tantos paratextos como fuera posible de las obras: portadas, pósteres, carátulas, reseñas e ilustraciones interiores, entre otros.

Tal como se detallará en cada caso en particular, la decisión sobre los criterios de inclusión también ha sido un aspecto importante en la configuración de las bases de datos. En este sentido, para ambos casos se decidió abarcar solamente las obras cuyas traducciones se han publicado o proyectado en España, descartando de este modo traducciones distribuidas solamente en Latinoamérica o en China. Esta decisión se debe a dos motivos estrechamente relacionados entre sí: por un lado, la necesidad de acotar el objeto de estudio, ya suficientemente amplio por sí mismo; y, por el otro, las dificultades para abarcar la producción de traducciones en contextos socioculturales ajenos al propio.

En cualquier caso, el proceso de recopilación de la información ha sido largo y laborioso, sobre todo por la dispersión de los datos y por la dificultad de encontrar información contrastada. De hecho, antes de introducir una obra en la base de datos se consultan diversas fuentes. En el caso de las obras literarias, siempre que sea posible, se consulta el libro en papel o, alternativamente, el catálogo de la editorial en línea y se buscan o toman imágenes de la portada y contraportada; también se tienen en cuenta las bases de datos de referencia como el ISBN, la BNE y el Index Translationum, o la información disponible en librerías virtuales. En el caso de las películas, se consultan páginas web de cine especializadas como Filmaffinity, IMDb y Movie Douban, páginas

Helena CASAS-Tost, Sara RoviRa-EsteVA y Mireia VARGAS-URPI Investigar la traducción de productos culturales chinos: retos y dificultades metodológicas...
CLINA

vol. 6-1, June 2020, 17-36

elSSN: 2444-1961

Ediciones Universidad de Salamanca - CC BY-NC-ND 
web de festivales y filmotecas, el «Catálogo de cine español» del Ministerio de Cultura y Deporte $^{8}$, y se buscan las imágenes de los pósteres y carátulas de VHS o DVD. Se priorizan las editoriales o distribuidoras de cine, aunque cuando estas fuentes no ofrecen información completa, se procura contrastar varias fuentes para subsanar y evitar reproducir errores, que son frecuentes incluso en fuentes de carácter oficial. Además, todas las entradas son revisadas como mínimo por dos investigadoras del grupo.

\subsection{Aspectos comunes en las dos bases de datos}

Si bien las dos bases de datos son hermanas y siguen una estructura similar, con información sobre el original primero y a continuación sobre la traducción, no son idénticas y funcionan de modo independiente. Desde el punto de vista metodológico comparten aspectos que merecen ser tenidos en cuenta en la creación de otros productos de investigación similares que tengan el chino como una de las lenguas de trabajo.

En primer lugar, los títulos se muestran en caracteres chinos simplificados, aunque también se permite la búsqueda por caracteres tradicionales. Asimismo, se incluye la transcripción en pinyin de acuerdo con sus normas ortográficas y la Guía de estilo para el uso de palabras de origen chino (Casas-Tost y Rovira-Esteva 2015). Sucede lo mismo con el nombre de los autores chinos, si bien en el caso de los directores de cine, además del nombre en caracteres y su transcripción en pinyin, se incluye también el nombre internacional tal como lo usa el propio director, y la búsqueda se puede realizar en cualquiera de las cuatro formas. A modo de ejemplo, el director taiwanés Hou Hsiao-Hsien se puede buscar a partir de su nombre escrito en caracteres tradicionales (侯孝賢), tal y como es habitual en Taiwán, aunque la visualización será por defecto en caracteres simplificados (侯孝贤). En cuanto a la transcripción, se puede buscar a partir del pinyin (Hou Xiaoxian) o tal y como es conocido internacionalmente (Hou Hsiao-Hsien). De este modo, se maximizan las posibilidades de éxito en la búsqueda de un autor, director o título en concreto.

En segundo lugar, ambas bases de datos detallan toda la información bibliográfica lo más completa posible, incluyendo las reediciones y distintas proyecciones de las que tenemos constancia ordenadas cronológicamente. Así, por ejemplo, si hay más de una edición de una misma traducción, o si la película se ha vuelto a proyectar en otras lenguas (por ejemplo, catalán) o en festivales, o se ha distribuido mediante otros formatos (VHS, DVD) o plataformas (Filmin, Netflix, etc.), se ha tratado de incluir también el año correspondiente.

En tercer lugar, todas las entradas cuentan con una breve sinopsis extraída de diversas fuentes. En el caso de las películas, por defecto y mediante una API, se ha recurrido a la web Filmaffinity. También proceden de otras fuentes en español (páginas

8. Consultable en línea en: http://infoicaa.mecd.es/CatalogolCAA/Buscador/BuscadorPeliculas

Helena CASAS-Tost, Sara Rovira-EsteVA y Mireia VARGAS-URPI Investigar la traducción de productos culturales chinos: retos y dificultades metodológicas...
CLINA

vol. 6-1, June 2020, 17-36

elSSN: 2444-1961

Ediciones Universidad de Salamanca - CC BY-NC-ND 
web de los festivales de cine, periódicos, etc.), o se han traducido del inglés o del chino a partir del resumen que aparece en IMDb o Movie Douban. En el caso de las obras literarias se ha priorizado el resumen que se encuentra en la contraportada o en la web de la editorial. Subsidiariamente, se ha recurrido a la web de librerías virtuales o blogs literarios. En todos los casos, se indica la fuente de donde se ha extraído la información. Se han revisado los resúmenes para garantizar su corrección lingüística, así como para asegurarnos de que la transcripción del pinyin no presenta errores. No obstante, en las películas provenientes de Hong Kong y Taiwán se ha optado por no alterar los nombres transcritos mediante otros sistemas, tal como se recomienda en Casas-Tost $(2015,48)$.

En cuarto lugar, otro aspecto común en las dos bases de datos son las imágenes. Siempre que se ha dispuesto de ellas, se han seleccionado por lo menos dos imágenes para cada entrada (correspondientes al original chino y a la versión traducida). Pulsando el botón de «Galería» se puede acceder a contraportadas, ilustraciones, portadas de ediciones posteriores, pósteres, carátulas de vídeo, entre otros. En el caso de clásicos de la literatura, si no se dispone de material gráfico de la edición original, se han incluido imágenes de ediciones posteriores para dar cuenta de la diversidad de presentaciones en la cultura de partida.

En quinto lugar, más allá de la información recopilada en las fichas de cada base de datos, otro aspecto importante es que ambas cuentan con una herramienta de búsqueda avanzada (figuras 1 y 2) que permite cruzar datos y filtrar los resultados utilizando varios criterios de búsqueda a la vez.

\section{Películas}

Traducciones | Originales

\begin{tabular}{|c|c|c|c|c|c|}
\hline Búsqueda & ¿Qué pelicula buscas? & Básica & Limpiar & & Buscar \\
\hline \multirow[t]{2}{*}{ Director } & & \multicolumn{2}{|l|}{ Género } & \multicolumn{2}{|c|}{ Año } \\
\hline & & & & ; & \\
\hline \multirow[t]{2}{*}{ Idioma } & & Formato & & \multicolumn{2}{|c|}{ Pais/región } \\
\hline & & & & ; & s \\
\hline \multirow[t]{2}{*}{ Traductor } & & Traducida o & & & \multirow{2}{*}{ Basada en novela } \\
\hline & & & & ; & \\
\hline \multirow[t]{2}{*}{ Festival } & & \multirow{2}{*}{\multicolumn{4}{|c|}{ Palabra clave }} \\
\hline & & & & & \\
\hline
\end{tabular}

Figura 1. Parámetros de la búsqueda avanzada en la base de datos

El cine chino traducido en España 


\section{Traducciones}

Añodir Exportar a XLSX

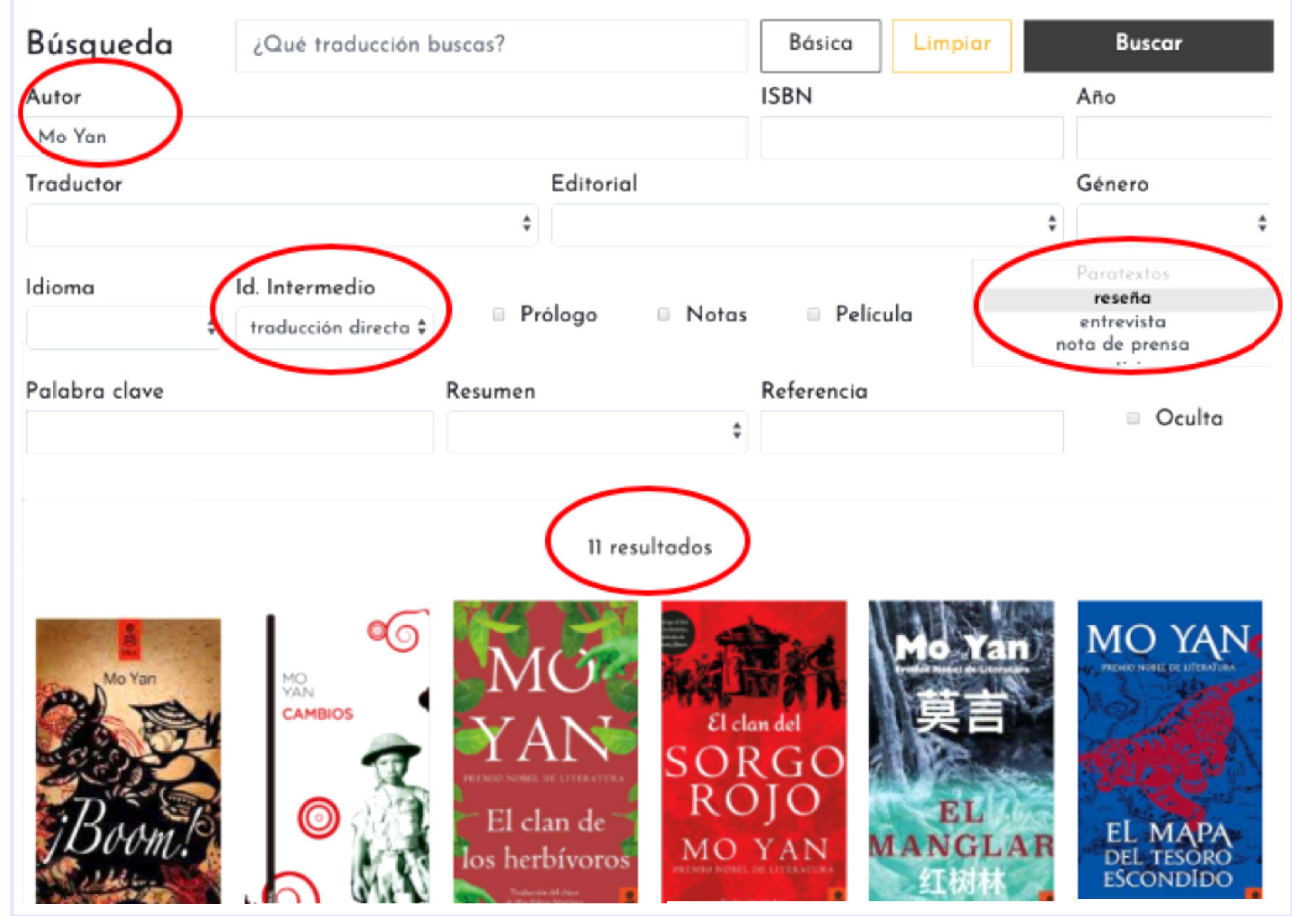

Figura 2. Resultados de una búsqueda avanzada en la base de datos La literatura china traducida en España

Ambas bases de datos están interrelacionadas. Cuando una película está basada en una novela se indica al final de la entrada; si, además, esta novela se ha traducido a alguna de las lenguas oficiales de España, se incluye el enlace a la ficha correspondiente en la base de datos de literatura. De manera similar, cuando una novela se ha llevado al cine, se hace constar esta información al final de su ficha; además, si se ha proyectado en España, se incluye el enlace a la entrada correspondiente en la base de datos de cine, permitiendo análisis más transversales de la producción y recepción de los productos culturales chinos en nuestro país.

Asimismo, ambas bases de datos permiten la descarga, a nivel interno, de un archivo en formato Excel con toda la información recopilada hasta el momento. Estas hojas de cálculo se descargarán periódicamente y se publicarán en acceso abierto

Helena CASAS-Tost, Sara ROVIRA-EsteVa y Mireia VARGAS-URPi Investigar la traducción de productos culturales chinos: retos y dificultades metodológicas...
CLINA

vol. 6-1, June 2020, 17-36

elSSN: 2444-1961

Ediciones Universidad de Salamanca - CC BY-NC-ND 
en el depósito digital de documentos de la UAB (DDD) ${ }^{9}$, facilitando así la consulta y manejo para satisfacer necesidades investigadoras concretas y permitir análisis más complejos de los datos.

\subsection{Aspectos específicos de la base de datos El cine chino traducido en España}

\subsubsection{Criterios básicos para la inclusión de las películas}

Las bases de datos parten de una perspectiva traductológica y, por lo tanto, el criterio básico para la inclusión de las películas es que el original incluya chino y haya llegado en algún formato traducido a España. Por lo tanto, en cuanto al lugar de origen, se incluyen películas producidas en China, Hong Kong, Taiwán o Singapur, así como coproducciones con otros países si en la versión original predomina el chino estándar, el cantonés, el tibetano u otras lenguas habladas en estos territorios. Cabe decir que en la ficha bibliográfica se recogen todas las lenguas que se hablan en la versión original.

Por lo que respecta a las lenguas de doblaje o subtitulación, la mayoría de las películas están traducidas al español, aunque hay una pequeña parte que lo están al catalán. En algún caso se han incluido también películas traducidas al inglés, si esta ha sido la lengua utilizada para su proyección en España. Se incluyen películas proyectadas en salas de cine, filmotecas u otros promotores culturales como los Institutos Confucio o festivales, en televisión o plataformas de vídeos a la carta, así como películas que se hayan distribuido en formato VHS, DVD o Blu ray.

Por último, cabe señalar que la base de datos se limita a largometrajes de ficción; no incluye cortometrajes ni documentales.

\subsubsection{Títulos de las películas}

Con el objetivo de ser lo más exhaustivas posible y facilitar la búsqueda, si una obra se ha comercializado con dos o más títulos en chino o en cualquiera de las lenguas meta, se han recogido todos separados mediante barras inclinadas. Por ejemplo, la película comercializada en España como Ninja contra los Shaolin consta de dos nombres en chino: 武侩 / 武僧 (Wu Kuai / Wu Seng).

En cuanto a las traducciones, se han incluido en primer lugar los títulos con los que se ha comercializado o proyectado la película en España: español, catalán o inglés.

9. Los archivos con toda la información que contenían las dos bases de datos a finales del 2019 son https://ddd.uab.cat/record/214779 para el cine y https://ddd.uab.cat/record/214778 para la literatura.

Helena CASAS-Tost, Sara Rovira-EsteVA y Mireia VARGAS-URPI Investigar la traducción de productos culturales chinos: retos y dificultades metodológicas...
CLINA

vol. 6-1, June 2020, 17-36

elSSN: 2444-1961

Ediciones Universidad de Salamanca - CC BY-NC-ND 
Sin embargo, dado el peso del inglés en la industria cinematográfica y, en particular, en la introducción del cine chino en España, el título en este idioma ha sido añadido, por defecto, en todas las películas. Por ejemplo, en la película 洞 (Dong), de Tsai MingLiang (蔡明亮), encontramos: El agujero | El forat | The Hole. En cambio, en la película 地下香 (Dixia Xiang), de Peng Fei (鹏飞), solamente encontramos el título en inglés, Underground Fragrances, puesto que así se ha distribuido en España.

\subsubsection{Géneros cinematográficos}

La búsqueda avanzada permite agrupar las películas por géneros. Para su asignación se ha seguido, mayoritariamente, la clasificación propuesta por IMDb. No obstante, se estimó oportuno añadir la categoría de «artes marciales» (武侠, wuxia), dado que es un género recurrente en la cinematografía china y, además, representa un porcentaje considerable de las películas del corpus.

\subsubsection{Información sobre la traducción}

En la traducción audiovisual, la información sobre la traducción es escasa. Raras veces aparece el nombre del traductor, la modalidad de traducción (doblaje o subtitulación en este caso) o la lengua desde la que se ha traducido en los créditos o en los datos más accesibles de las películas. A menudo es difícil saber si la traducción ha sido realizada directamente del chino o si se ha llevado a cabo por mediación de otras lenguas como el inglés, hecho muy habitual en festivales de cine. Por consiguiente, estos datos solo se han podido incluir cuando se ha dispuesto de información contrastada.

\subsubsection{Distribución}

Los datos de distribución se incluyen solamente para películas que se han proyectado en salas de cine. Se han extraído a partir de diferentes fuentes, entre ellas el catálogo de la BNE, las páginas web de las propias distribuidoras y el "Catálogo de Cine Español» del Ministerio de Cultura y Deporte, de donde se ha recopilado también la información sobre el número de espectadores, aunque esta información no aparece sistemáticamente para todas las películas ni resulta siempre fiable.

\subsubsection{Formatos}

La búsqueda avanzada por formatos incluye tres categorías: a) televisión, para películas que se han programado en las cadenas de televisión; b) plataformas de vídeos

Helena CASAS-Tost, Sara Rovira-EsteVa y Mireia VARGAS-URPI Investigar la traducción de productos culturales chinos: retos y dificultades metodológicas...
CLINA

vol. 6-1, June 2020, 17-36

elSSN: 2444-1961

Ediciones Universidad de Salamanca - CC BY-NC-ND 
a la carta, como Netflix, Filmin, Imagenio, o Movistar+, entre otras; y c) disco o cinta, que engloba VHS, DVD o Blu ray.

En el campo de formatos se encuentra también, entre paréntesis, información sobre la traducción de la película, puesto que en algunos casos difiere de la traducción para salas de cine o festivales.

En relación con las plataformas de vídeos a la carta, no siempre es posible saber en qué momento se estrenaron o dejaron de ser accesibles. En este sentido, la base de datos simplemente recoge la información de que las películas han sido accesibles a través de estos medios en el año o años en el que se han consultado las plataformas, información que se indica entre paréntesis.

\subsubsection{Festivales}

Puesto que los festivales de cine son una de las vías de entrada más importante del cine chino en España (Casas-Tost y Rovira-Esteva 2019, 592), la base de datos recopila todas las películas que han sido proyectadas en festivales españoles, entre los que destacan los centrados en cine asiático, pero también incluye los generalistas de todo el Estado. El listado completo lo componen AFFBCN ${ }^{10}$, Fancine: Festival de Cine Fantástico (Málaga), Festival de Cine de Las Palmas de Gran Canaria, Festival de San Sebastián, Festival Internacional de Cine de Gijón, Festival Nits de Cinema Oriental de Vic, Lychee International Film Festival, Semana Internacional de Cine de Valladolid y SITGES: Festival Internacional de Cine Fantástico de Catalunya. La búsqueda avanzada permite buscar todas las películas proyectadas en cada uno de los festivales. Dada su importancia como puente hacia España, también hemos incluido los festivales de cine de Berlín, Venecia y Cannes, siempre que las películas allí proyectadas hayan llegado también a nuestro país.

A pesar de no ser festivales, se han incluido también las siguientes instituciones en esta categoría, por tratarse de entes culturales que han programado, con cierta frecuencia, ciclos de cine en los que se proyectan películas de origen chino: Filmoteca de Andalucía, Filmoteca Caja de Canarias, Filmoteca de Catalunya, Fundación Instituto Confucio de Barcelona, Filmoteca de Murcia, Filmoteca de Extremadura, Filmoteca de Valencia y La Mostra de CINEBAIX en Sant Feliu de Llobregat. Además, se está trabajando para incluir las filmotecas de todas las comunidades autónomas en esta sección y se espera poder separarlas de la lista de festivales en el futuro.

En todos los casos, se indica el año o años en que cada película se ha proyectado en estos espacios, ya que no es extraño encontrar películas exhibidas por el mismo festival o promotor cultural más de una vez. Sin embargo, a diferencia del cine y otros

10. Festival de Cine Asiático de Barcelona, heredero de otras fórmulas previas que se iniciaron en 1999.

Helena CASAS-Tost, Sara ROVIRA-EsteVA y Mireia VARGAS-URPI Investigar la traducción de productos culturales chinos: retos y dificultades metodológicas...
CLINA

vol. 6-1, June 2020, 17-36

elSSN: 2444-1961

Ediciones Universidad de Salamanca - CC BY-NC-ND 
formatos, no se especifica la modalidad de traducción, puesto que se trata siempre de la subtitulación.

En definitiva, cabe señalar que los diferentes canales de distribución (cine, formatos domésticos y festivales) no son excluyentes entre sí, sino que se refuerzan unos a otros y se retroalimentan.

\subsection{Aspectos específicos de la base de datos La literatura china traducida en España}

\subsubsection{Criterios básicos para la inclusión de las obras}

Esta base de datos parte también de una perspectiva traductológica y, por lo tanto, el criterio básico para la inclusión de las obras es que hayan sido originalmente escritas en chino estándar (o alguna variante sinítica) y su traducción haya sido publicada en España. Por consiguiente, la base de datos actual no contempla las traducciones al español publicadas en países latinoamericanos, Andorra o China. En cuanto al lugar de origen, se incluyen obras de autores procedentes de China continental, Hong Kong, Taiwán, Singapur y la diáspora china. Por lo que respecta a las lenguas de llegada, se incluyen todas las obras de las que se tiene constancia que han sido traducidas al castellano, catalán, euskera y gallego. Respecto a los formatos, solo se contemplan obras publicadas en forma de libro que dispongan de un ISBN, por lo que otros formatos, como la publicación en revistas y páginas web o las autopublicaciones sin ISBN, han quedado excluidos.

Solo se han incluido traducciones, evitando los textos explícitamente presentados como versiones libres. Sin embargo, a veces es difícil discernir si el texto en la lengua de llegada es una traducción propiamente dicha o un texto nuevo inspirado en un original chino. En caso de que una misma obra cuente con más de una traducción, se ha hecho una entrada específica para cada una, agrupando sus diferentes ediciones, si las hubiere, incluso si han sido publicadas por diferentes editoriales. Esto permite comparar los diferentes paratextos asociados a una misma traducción y, en el caso de textos con muchas ediciones, tener agrupados los datos de su evolución para su análisis diacrónico. Por el contrario, se han elaborado entradas diferentes para ediciones revisadas o cuando el título ha cambiado.

\subsubsection{Información relativa al original}

Ya sea por tratarse de antologías o de obras anónimas de tradición oral, muchas traducciones no se corresponden con un único original o, por lo menos, no consta. En estos casos, veremos en el campo correspondiente «Sin original de referencia». En obras de autoría colectiva, se han hecho constar los nombres de todos los autores y,

Helena CASAS-Tost, Sara RoviRa-EsteVA y Mireia VARGAS-URPI Investigar la traducción de productos culturales chinos: retos y dificultades metodológicas...
CLINA

vol. 6-1, June 2020, 17-36

elSSN: 2444-1961

Ediciones Universidad de Salamanca - CC BY-NC-ND 
en caso de no haber podido verificar la identidad de todos ellos, se ha marcado con la fórmula «et al.». Las obras de autor originalmente desconocido constan como anónimas.

\subsubsection{Géneros literarios}

Los géneros literarios incluidos son: poesía, filosofía, teatro, cuento, novela, ensayo y cómic. El género narrativo se ha dividido en cuento y novela siguiendo el criterio chino de la longitud más que el de la edad del público al que va dirigido. Así, todas las obras etiquetadas como «cuento» corresponderán a cuento o narrativa corta (duanpian xiaoshuo, 短篇小说), incluyendo también cuentos infantiles, mientras que «novela» se referirá a obras de ficción de mayor extensión, es decir, lo que en chino se conoce como zhongpian xiaoshuo (中篇小说) y changpian xiaoshuo (长篇小说). En cuanto al ensayo, solo se incluye el literario, descartándose aquel de carácter académico. Así, asumimos el concepto integrador de literatura tal como lo aplica Arbillaga $(2003,14)$. En la mayoría de los casos a cada obra se le ha asignado un solo género, salvo algunas excepciones, como Teatro y pensamiento de Gao Xingjian, puesto que incluye una obra de teatro y piezas de ensayo del mismo autor. Sin embargo, toda clasificación presenta problemas a la hora de su aplicación, no solo porque los límites entre categorías son difusos, sino porque un mismo texto puede recibir etiquetas distintas en función de la cultura que las otorgue. Por ejemplo, ¿deberían religión y política considerarse diferentes tipos de filosofía o pensamiento? Y, en este sentido, ¿podrían clasificarse Los ensayos filosóficos de Mao Zedong también dentro de filosofía? Por otro lado, ¿qué etiqueta merece la crónica histórica, género literario por excelencia en la cultura china? Todas esas cuestiones no son baladíes a la hora de estudiar la transmisión del conocimiento entre culturas a través de la traducción porque son elementos que también participan en la construcción de la imagen del Otro. No está de más señalar que estas etiquetas son dinámicas en la medida que nuevos géneros no contemplados hasta el momento podrían incorporarse en el futuro. Así, por ejemplo, el cómic ha sido incluido recientemente ante la constatación de que se trata de un género al alza desde el punto de vista de la traducción del chino al español.

\subsubsection{Datos relativos a la traducción}

Este apartado incluye tres bloques de información. En primer lugar, se indica el nombre del traductor, si la traducción es directa o mediada, la lengua de la versión intermedia, si la hubiere, y el nombre del traductor de la versión intermedia, si consta. En segundo lugar, se presentan los datos bibliográficos básicos de las diferentes ediciones existentes de esa traducción. Por lo tanto, las versiones hechas por traductores diferentes o a diferentes lenguas constan en la base de datos como entradas

Helena CASAS-Tost, Sara ROVIRA-EsteVA y Mireia VARGAS-URPI Investigar la traducción de productos culturales chinos: retos y dificultades metodológicas...
CLINA

vol. 6-1, June 2020, 17-36

elSSN: 2444-1961

Ediciones Universidad de Salamanca - CC BY-NC-ND 
diferentes. Finalmente, también se facilita información sobre los tipos de paratextos disponibles de cada traducción: peritextos (como notas del traductor, introducciones e ilustraciones) y epitextos (por ejemplo, reseñas, entrevistas o presentaciones públicas de la traducción). Siempre que se ha dispuesto de ellos, se han incluido en la base de datos para facilitar su consulta. Consideramos que la disponibilidad y agrupación de estos paratextos son un aspecto innovador y representan un importante valor añadido respecto a otras iniciativas parecidas, ya que aportan un complemento cualitativo muy valioso para el estudio de la historia de la traducción de la literatura china en España, así como de su recepción a través de la crítica profesional o amateur.

A pesar de que la situación es considerablemente mejor que en el caso de la traducción audiovisual, hay que destacar que la información disponible sobre los traductores literarios también es escasa, dado que a menudo no aparecen en las fichas bibliográficas ni en la página de créditos de los libros mismos, especialmente en el caso de las ediciones más antiguas. En este sentido, no siempre es posible dilucidar si la traducción ha sido hecha directamente del chino o si se ha realizado por mediación de otras lenguas, por lo que este dato solo se ha recogido cuando se disponía de la información contrastada. En caso de tratarse de una traducción mediada, siempre que ha sido posible se ha hecho constar el nombre del traductor y la lengua de la versión intermedia. Las traducciones hechas directamente del chino por traductores de origen chino también se han considerado traducciones directas.

Esta falta de rigurosidad y transparencia en la información relativa a la traducción no es casual ni anecdótica, ya que se trata de una práctica que responde principalmente a dos motivos. Por una parte, al escaso valor que se ha atribuido tradicionalmente a la labor del traductor, al cual se ha invisibilizado sistemáticamente del proceso editorial hasta que en España ha sido obligatorio por ley reconocer sus derechos. Sin embargo, aún no nos encontramos en la situación que podríamos considerar ideal o deseable. En palabras de Recio Ariza et al. (2013, 168): «[s]i bien es cierto que la Ley de la Propiedad Intelectual ha mejorado mucho las condiciones del traductor, no es menos cierto que desgraciadamente en España ésta se incumple con frecuencia». Por otra parte, la falta de información relativa a la traducción también se debe al recurso a traducciones intermedias por falta, inicialmente, de traductores lingüísticamente competentes para traducir directamente del chino y, posteriormente, para ahorrar en los costes. Siendo conscientes de que la traducción mediada hecha por un traductor desconocedor de la cultura original puede afectar a la calidad del texto meta y dar lugar a un menor prestigio social, los editores a menudo ocultan esta información al lector. Esta práctica, denunciada ya por Marin-Lacarta (2012), sigue siendo común entre muchas de las editoriales de nuestro corpus y, lamentablemente, tiene consecuencias importantes para proyectos como el que nos ocupa.

Precisamente para poner en valor la traducción directa del chino, que siempre implica una mayor dificultad que traducir a partir de una lengua cercana, y contribuir a la visibilidad de la figura del traductor, la base de datos incorpora una ficha con una nota biográfica para cada uno de los traductores que tienen al menos una traducción

Helena CASAS-Tost, Sara RoviRa-EsteVA y Mireia VARGAS-URPI Investigar la traducción de productos culturales chinos: retos y dificultades metodológicas...
CLINA

vol. 6-1, June 2020, 17-36

elSSN: 2444-1961

Ediciones Universidad de Salamanca - CC BY-NC-ND 
directa del chino. En esta ficha se incluyen también enlaces a entrevistas que se les hayan realizado sobre su labor como traductores o a sus páginas web personales.

En cuanto a los datos de la traducción, se presentan tal como aparecen en el libro publicado, se adecúen o no a las normas ortográficas del pinyin. Por ejemplo, así ocurre cuando un autor como Chen Guanzhong (陈冠中) se da a conocer fuera de China con un nombre internacional (Chan Koonchung) o cuando se emplea una transcripción anterior a la adopción internacional del pinyin en ediciones antiguas de, por ejemplo, el Dao De Jing (道德经) de Laozi (老子), que encontramos como Tao Te Ching de Lao Tzu, entre otros. Además del título con el que se ha publicado, el año, la editorial y el lugar de publicación, se hace constar la colección, si la hubiere. Por este motivo, si lo que se quiere es identificar todas las traducciones existentes de un mismo original, se recomienda utilizar la opción de búsqueda a partir del título original en chino (en caracteres o en pinyin), no a partir de la traducción.

\section{CONCLUSIONES}

Estas dos bases de datos, enmarcadas en los Estudios de Traducción e Interpretación, permiten llevar a cabo estudios descriptivos orientados al discurso, estudios de la historia de la traducción, así como también estudios de sociología de la traducción o de la recepción de las traducciones y la paratraducción, a través de las portadas, carátulas u otros paratextos, así como de datos del número de ediciones, en el caso de la literatura, o de diversidad de canales de proyección, espectadores o montante de la recaudación, en el caso del cine. Asimismo, sientan un precedente en cuanto a una posible metodología para la creación de futuras bases de datos con esta y otras combinaciones lingüísticas. Estas bases de datos ofrecen mucha más información que el resto de las bases de datos existentes, por lo que suponen un avance importante desde el punto de vista bibliográfico y traductológico.

Otra de las aportaciones más importantes de este proyecto es la información relativa a la traducción, no siempre fácil de encontrar en literatura y especialmente difícil de hallar en el caso del cine. De hecho, para obtener la información sobre el traductor, en la modalidad de subtitulación a menudo es necesario esperar hasta los créditos del final de la película (por ejemplo, en el caso de las salas de cine y plataformas como Netflix) y en la de doblaje lo más probable es que esta información ni siquiera aparezca. En el caso de la base de datos de literatura, dado que esta información es relativamente más accesible, se ha podido incluso añadir una ficha con una biografía breve de una parte de los traductores, aspecto que puede ser muy útil para realizar estudios sobre sociología de la traducción del chino en España.

En relación con los estudios previos, el haber dispuesto de la base de datos de literatura habría permitido, por ejemplo, ampliar los corpus de estudio en Marin-Lacarta (2012; 2014; 2018) y Wang Chenying (2013; 2016). Ahora estamos en disposición de

Helena CASAS-Tost, Sara ROVIRA-EsteVA y Mireia VARGAS-URPI Investigar la traducción de productos culturales chinos: retos y dificultades metodológicas...
CLINA

vol. 6-1, June 2020, 17-36

elSSN: 2444-1961

Ediciones Universidad de Salamanca - CC BY-NC-ND 
analizar si las conclusiones a las que llegan estas autoras sobre la traducción indirecta (Marin-Lacarta 2012; 2014) o sobre la escasez de traducciones del chino (Wang Chenying 2013; 2016) son extrapolables a un corpus más amplio y exhaustivo. En el caso de estudios sobre cine chino, la base de datos podría utilizarse para conseguir la correcta identificación de las películas, con información precisa sobre los títulos (en chino, en pinyin, en la forma internacional en inglés y en español o catalán cuando también se ha traducido a estas lenguas), pudiendo mejorar así las carencias en los aspectos formales detectados en Sazatornil y Alonso (2012).

A pesar de partir de la perspectiva de los Estudios de Traducción, estas bases de datos pueden constituir también una aportación significativa para otras disciplinas (por ejemplo, para los Estudios Culturales y la Literatura o el Cine Comparados), gracias a su marcado carácter interdisciplinar. Además, proporcionan información sobre los hábitos de consumo de productos culturales chinos, gracias a la clasificación por géneros, a la información sobre el número de ediciones o proyecciones y a los datos relativos al número de espectadores en el caso del cine. Desde el punto de vista metodológico, el enfoque de carácter colaborativo, interdisciplinar y de ciencia en acceso abierto establece un modelo de referencia para las Humanidades Digitales, en general, y la Sinología, en particular.

Más allá de las aportaciones en el ámbito académico, estas bases de datos suponen un claro ejemplo de transferencia de conocimiento a la sociedad, no solo porque ponen al alcance del gran público, cinéfilos, bibliófilos y sinófilos una herramienta de consulta puntual fácil e intuitiva, sino también porque ofrecen un valioso recurso a editores, técnicos culturales o traductores para conocer el estado de la cuestión y ayudarles en la toma de decisiones bien informadas.

Ninguna investigación está exenta de limitaciones. En este sentido y como ya se ha mencionado, actualmente las bases de datos solamente incluyen las obras cuyas traducciones se han publicado o proyectado en España, aunque no se descarta incluir en el futuro traducciones distribuidas también en Latinoamérica o en China. Otros parámetros que podrían considerarse más adelante serían: a) ampliar la base de datos de cine a otros géneros, como documentales y cortometrajes; b) añadir otras modalidades de traducción audiovisual, como la audiodescripción o el subtitulado para sordos; c) incluir información sobre los premios concedidos a las películas, puesto que también son un elemento determinante en la selección de filmes que se traducen, igual que sucede con el premio Nobel en el caso de la literatura.

Para concluir, presentar en sociedad estos dos productos de investigación y compartirlos en acceso abierto supone la culminación de muchos años de trabajo que marca un punto de inflexión. A partir de ahora se inicia una nueva etapa en la que las posibilidades de las bases de datos para la consulta e investigación se multiplican y van mucho más allá de las que puedan originarse en el seno del grupo que las ideó y puso en marcha.

Helena CASAs-Tost, Sara Rovira-EsteVA y Mireia VARGAS-URPI Investigar la traducción de productos culturales chinos: retos y dificultades metodológicas...
CLINA

vol. 6-1, June 2020, 17-36

elSSN: 2444-1961

Ediciones Universidad de Salamanca - CC BY-NC-ND 


\section{BIBLIOGRAFÍA}

Arbillaga Guerrero, Idoia. 2003. La literatura china traducida en España. San Vicente del Raspeig: Universidad de Alicante.

CASAS-Tost, Helena. 2015. «Antropónimos». En Guía de estilo para el uso de palabras de origen chino, editado por Helena Casas-Tost y Sara Rovira-Esteva, 46-49. Madrid: Adeli. URL: https://ddd.uab.cat/record/180644

CAsAs-Tost, Helena y Sara RoviRA-Esteva. 2015. Guía de estilo para el uso de palabras de origen chino. Madrid: Adeli. URL: https://ddd.uab.cat/record/180644

Casas-Tost, Helena y Sara RoviRa-Esteva. 2019. "Chinese Cinema in Spain. An Overview through Audiovisual Translation». Babel 65 (4): 581-603. https://doi.org/10.1075/babel.00109.cas

Casas-Tost, Helena, Sara Rovira-Esteva, Mireia Vargas-Urpi e Irene Tor-Carroggio. 2019. «El cine chino traducido en España». Base de datos en acceso abierto. Acceso el 2 de febrero de 2020. https://dtieao.uab.cat/txicc/cine

CHANG Yun-CH. 2012. Estudio comparativo sobre la traducción del lenguaje no verbal del chino y dos versiones en español el caso de la novela Xi You Ji. Tesis Doctoral. Universitat Autònoma de Barcelona. http://hdl.handle.net/10803/96230

Codó Martínez, Jordi. 2009. «Llegada y consumo de cines asiáticos en Occidente». InterAsia Papers 10: 1-28.

GarcíA-NobleJAS, Gabriel. 2010. «La traducción chino-español en el siglo XX: Marcela de Juan (1)». El Trujamán. Revista diaria de traducción. Acceso el 2 de febrero de 2020. https://cvc. cervantes.es/trujaman/anteriores/mayo_10/12052010.htm

GarcíA-NobleJas, Gabriel. 2011. "La traducción del chino al español en el siglo XX: Carmelo Elorduy (1)». El Trujamán. Revista diaria de traducción. Acceso el 2 de febrero de 2020. https:// cvc.cervantes.es/trujaman/anteriores/marzo_11/23032011.htm

GarcíA-Noblejas, Gabriel. 2012a. "Orígenes de la traducción chino-español: Fray Juan Cobo (I)». El Trujamán. Revista diaria de traducción. Acceso el 2 de febrero de 2020. https://cvc. cervantes.es/trujaman/anteriores/septiembre_12/11092012.htm

GarcíA-NobleJAS, Gabriel. 2012b. «Orígenes de la traducción chino-español: Fray Domingo Fernández de Navarrete (I)». El Trujamán. Revista diaria de traducción. Acceso el 2 de febrero de 2020. https://cvc.cervantes.es/trujaman/anteriores/noviembre_12/13112012.htm

Ku Meng-hsuan. 2006. La traducción de los elementos lingüísticos culturales (chino-español): Estudio de 红楼梦 [Sueño en las estancias rojas]. Tesis Doctoral. Universitat Autònoma de Barcelona. https://ddd.uab.cat/record/36620

MARIN-LACARTA, Maialen. 2012. «Mediación, recepción y marginalidad: Las traducciones de literatura china moderna y contemporánea en España. Tesis Doctoral». INALCO, Ecole Doctorale - Langues, littératures et sociétés du monde, Équipe ASIEs, Doctorat de Traducció i Estudis Interculturals, Departament de Traducció i Interpretació, Universitat Autònoma de Barcelona. http://hdl.handle.net/10803/96261

MARIN-LACARTA, Maialen. 2014. «Reclamos reiterativos en las traducciones de literatura china moderna y contemporánea en España». En Estudios de Traducción e Interpretación Chino-Español, editado por Gabriel García-Noblejas Sánzhez-Cendal, 57-101. Granada: Universidad de Granada.

MARIN-LACARTA, Maialen. 2018. «Mediated and Marginalised: Modern and Contemporary Chinese Literature Translations in Spain (1949-2010)». Meta: Translators' Journal 63 (2): 306-321.

Helena CASAS-Tost, Sara RoviRa-ESTEVA y Mireia VARGAS-URPI

Investigar la traducción de productos culturales chinos: retos y dificultades metodológicas...
CLINA

vol. 6-1, June 2020, 17-36

elSSN: 2444-1961

Ediciones Universidad de Salamanca - CC BY-NC-ND 
Mı TIAN. 2017. «Las traducciones de poesía china de Marcela de Juan». Estudios de Traducción 7: 111-120. https://doi.org/10.5209/ESTR.58197

MI TIAN. 2018. «Marcela de Juan (黄玛赛): Los inicios de los trasvases culturales entre China y España en el siglo XX». Quaderns: Revista de Traducció 25: 203-16.

ORLANDO, Jorge. 2013. «Literatura china: una breve lista de obras en español». Acceso el 2 de febrero de 2020. http://www.jorgeorlandomelo.com/bajar/literaturachinaespanol.pdf

Recio Ariza, María Ángeles, Ana B. Ríos Hilario, Ovidi Carbonell Cortés y luis Hernández Olivera. 2013. «Traducción y autoría: la evolución de los derechos de autor en la figura del traductor». En: Traducción y autoría: la evolución de los derechos de autor en la figura del traductor, editado por María Ángeles Recio Ariza, Ana B. Ríos Hilario, Ovidi Carbonell Cortés y Luis Hernández Olivera, 167-173. Salamanca: Ediciones Universidad de Salamanca.

Ortells-Nicolau, Xavier. s.d. «Chinese Film Database». Acceso el 2 de febrero de 2020. https:// chinesefilmdatabase.wordpress.com/

Planas, Ricard. 2019. Historia del cine chino. Córdoba: Almuzara.

Poupaud, Sandra, Anthony PYM y Ester ToRRES SIMÓN. 2009. «Finding Translations on the Use of Bibliographical Databases in Translation History». Meta: Translators' Journal 54 (2): 264-78.

Rovira-Esteva, Sara, Helena CASAS-Tost, Irene Tor-Carroggio y Mireia Vargas-Urpí. 2019. «La literatura china traducida en España». Base de datos en acceso abierto. Acceso el 2 de febrero de 2020. https://dtieao.uab.cat/txicc/lite doi: 10.5565/ddd.uab.cat/214778.

Rovira-Esteva, Sara y Javier Franco Aixelá. 2018. "Bibliometric Tools (Evaluation, Mapping, Research Funding)». En History of Translation Knowledge: A Dictionary, editado por Lieven D'hulst e Yves Gambier, 177-22. Amsterdam: John Benjamins.

SazAtornil, Miguel y María Cruz Alonso. 2012. Cine chino. Breve mirada histórica. Madrid: Imagine Ediciones.

WANG ChenyING. 2013. "La traducción de la literatura chinoamericana en lengua española». Tesis Doctoral. Universidad de Salamanca.

WANG CHENYING. 2016. «La traducción de la literatura china en España». Estudios de traducción 6, 65-79. https://doi.org/10.5209/ESTR.53004

Wu Sian-Huang. 2013. Traducción y recepción de la subtitulación chino-español. Análisis de la cultura lingüística como referente cultural. Tesis Doctoral. Universitat Autònoma de Barcelona. http://hdl.handle.net/10803/120546

\section{AGRADECIMIENTOS}

El presente trabajo ha sido posible gracias a la financiación de la Fundación Instituto Confucio de Barcelona y al apoyo del Departamento de Traducción e Interpretación y de Estudios de Asia Oriental de la Universidad Autónoma de Barcelona, así como del grupo de investigación Transmedia Catalonia (2017SGR113 ).

Helena CASAS-Tost, Sara RoviRa-EsteVA y Mireia VARGAS-URPI

Investigar la traducción de productos culturales chinos: retos y dificultades metodológicas...
CLINA

vol. 6-1, June 2020, 17-36

elSSN: 2444-1961

Ediciones Universidad de Salamanca - CC BY-NC-ND 